\title{
Research on Novice College Teacher's Professional Development Based on Personal Knowledge Management
}

\begin{abstract}
Qi Wu
Jiujiang University, Jiujiang, Jiangxi, China

Corresponding author. Email: wuqiqiwu@126.com

ABSTRACT

Novice college teachers' less motivated professional development is investigated by integrating massive amounts of fragmented information into establishing their knowledge system and information resource database. The deficiency of such poor knowledge transformation is firstly surveyed through China's CNKI database to offer a visualized statistic analysis of the status of their professional development and new challenges of their personal knowledge management. Then four levels of personal knowledge management are constructed in a progressive way. The results show that a new model of knowledge cycle development network towards their personal knowledge management needs to be established for young teachers to comply with the development trend of information technology, and to improve their professional knowledge system as well as their ability and competition. The role of this model is fulfilled by applying four strategies to make sure that good personal knowledge management can drive them to realize personal values and sustainable development in multimedia era.
\end{abstract}

Keywords: novice college teacher, professional development, personal knowledge management, knowledge cycle development network

\section{INTRODUCTION}

The research on knowledge management firstly originates from the discussion on improving the benefits of enterprises. The purpose is to excavate and develop the knowledge assets of the organization to achieve its own goals. The knowledge management includes both explicit/textual knowledge and implicit/subjective knowledge [1]. It should be pointed out that there are relatively few researches on knowledge management for the professional development of high education teachers. Traditionally, teacher development is usually understood as an external force, such as the process of growing up under the training of normal schools, post-service training institutions, etc., while ignoring the teacher's subjective awareness and initiative in self-growth.

In China, today's professional development of college teachers has an obvious single knowledge orientation [2]. Notably, many novice (young) teachers do not take practical knowledge as the basis for their professional development, or further promotes their own professional development through self-reflection and peer cooperation, and so forth. From the perspective of the impact of information technology on the professional development of novice college teachers, they are not much motivated to actively integrate education and information technology, and lack development awareness. At the same time, many novice teachers cannot effectively integrate massive amounts of fragmented information into establishing their own knowledge system and information resource database. They also ignore the mining of tacit knowledge and knowledge transformation to enhance the value of personal knowledge. Nowadays, new media and new teaching methods that are widely used to change traditional education is the general trend in future. Therefore, in the era of 'Internet + Education', the topic of professional development of new college teachers attracts more and more attention.

\section{THE STATUS QUO OF THE PROFESSIONAL DEVELOPMENT OF NOVICE COLLEGE TEACHERS AND CHALLENGES}

This study conducted a survey through China's 
CNKI database (www.cnki.net) on October 5, 2021. The two subject terms entered are 'Teacher Professional Development' and 'Knowledge Management'. The publication year is between 2000 and 2020. The core databases used are CSSCI (Chinese Social Sciences Citation Index) and CSCD (Chinese Science Citation Database). The retrieved results are 57 research papers, and the research themes involved are shown in the following Figure 1:

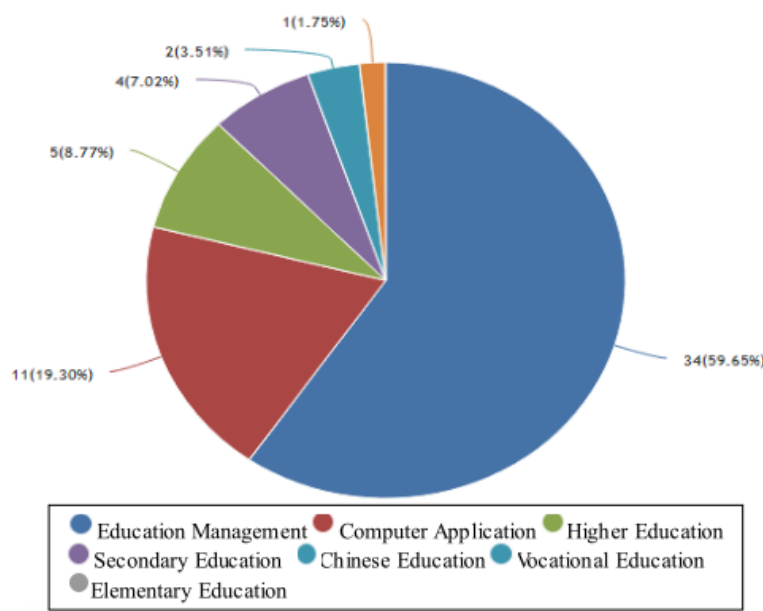

Figure 1 Theme Distribution of 57 Papers (2000-2020)

1) In general, Figure 1 shows that the number of articles that scholars have studied the professional development of teachers in combination with knowledge management is only 57, and among them there are only 5 articles that are related to research on college/university teachers, accounting for $8.77 \%$ on the whole. However, the research on novice teachers in colleges/universities is still rare.

2) One major reason is that mass information/big data and knowledge management are tricky to deal with in the era of 'Internet ${ }^{+}$' and have become a major challenge for the professional development of novice teachers in colleges and universities. With the influx of huge knowledge and information, they are prone to be in anxiety in the process of selecting them. Owing to work pressure and job burnout, their job positioning is relatively vague too; in the process of academic research, it is difficult for them to achieve the optimization of knowledge sharing and create new knowledge.

3) Moreover, due to the particularity of their academic profession and social development, novice teachers in colleges/universities are required to acquire a variety of knowledge. However, colleges/universities in mainland China lack real big knowledge bases for use. The knowledge bases on the Internet are not owned by individual colleges or universities. Few organizations have independent knowledge bases for the novice teachers to transfer their knowledge.

Novice college/university teachers face both challenges and opportunities for their professional development. 'Internet + education' is a new educational form that combines Internet technology and education with the continuous development of science and technology.

1) Today, Internet has changed and even subverted individual educators and organizations. Cloud computing, big data, Internet of Things, artificial intelligence and other technologies have subverted the original model of personal survival and education operation. With the rapid flow of information, the storage of knowledge has also changed, and education has become more and more digital and networked.

2) The Internet provides a broader platform for education. New educational forms such as micro-classes, flipped classrooms, and MOOCs have made Internet teaching more popular, and the era of 'everyone as a teacher' is approaching.

3) The Internet is increasingly showing the characteristics of fragmentation, rich media and contextualization. The fact that educators use the Internet to collect, classify and build knowledge bases has become a trend in the new era. They need more time, energy and chances to establish their integrated personal knowledge systems.

4) At the same time, through the 'Internet + education' action and by means of scientific and technological outcomes, teachers can break the boundaries of time and space, realize the sharing of high-quality educational resources, and better promote the development of fair education. Therefore, college teachers must vigorously develop wisdom education and enhance learners' ability to use the Internet for communication, comprehensive induction, statistical analysis, and transformation, so as to achieve a greater improvement in learning quality and efficiency.

\section{LEVELS AND IMPLICATIONS OF PERSONAL KNOWLEDGE MANAGEMENT}

\subsection{Four Levels of Personal Knowledge Management}

Personal knowledge management is about the management of the acquisition, storage, sharing and utilization of personal knowledge [3]. It is a requirement for teachers' professional development ability in the current era of knowledge economy. The four different elements that have a transformative relationship with knowledge can be divided into four levels, and they are shown as follows: data-information-knowledge-wisdom in a progressive way from lower value to higher value. They are related to each other, forming a sequence from 'shallow to deep' and 'easy to difficult', as indicated in the following Figure 2. 


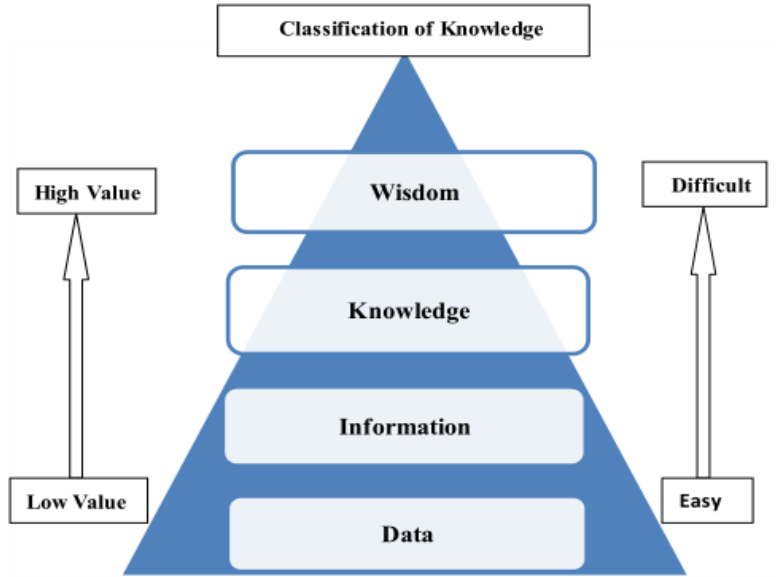

Figure 2 Classification of Knowledge

1) Data: The data layer is the most basic. It is scattered, unrelated, and objective facts about events. Data is usually only used as storage, such as the price of goods.

2) Information: The information layer can be classified and quickly edited, which is a screening summary of the data layer. It is believed that information is a type of data that has been given relevance and purpose, which means that the information is an orderly arrangement of data that already has a certain meaning. For example, music symbols are data, and the orderly arrangement is converted into a certain tone and rhythm, which is called music information.

3) Knowledge: Knowledge is a state of knowing, a fact that is mastered [4]. It is a summary of people's understanding, discovery, or learning, and it can also be derived from experience. Knowledge can be created, and it will disappear over time. Objectively understanding knowledge is to form a set of one's own methodology after understanding the content of the information layer, which can produce basic behavioral guidance for current problems.

4) Wisdom: The knowledge layer teaches people how to use data to solve current problems, and the wisdom layer requires people to have the ability to use it at any time and anywhere, that is, to have certain predictive and innovative abilities [5]. A basic problem of knowledge management is the classification of knowledge. From the perspective of application, the OECD (The Organization for Economic Co-operation and Development) divides knowledge into 4 categories: factual knowledge (knowwhat), principle knowledge (know-why), skill knowledge (know-how) and interpersonal Knowledge (know-who). From the perspective of cognition, knowledge can be divided into explicit knowledge and tacit knowledge. Explicit knowledge means that an individual can express it clearly in language and text, and impart it to others objectively. Tacit knowledge refers to knowledge that is rooted in personal experience and difficult to express in words and judgments or intuitions that cannot be easily described, such as talents and morals. Tacit knowledge management emphasizes the use of interpersonal communication to enhance the effect of knowledge innovation. Explicit knowledge management concerns with the use of information tools to increase the exchange rate of knowledge circulation and diffusion. In a broad sense, knowledge management is to transform tacit knowledge into explicit knowledge and increase the diffusion and circulation of explicit knowledge. The first two belong to explicit knowledge, and the latter two belong to tacit knowledge. Dynamically circulating, explicit knowledge and tacit knowledge can be transformed into each other.

\subsection{The Implication of Knowledge Management Theory to Teacher's Professional Development}

1) The integration of systematic explicit knowledge should be strengthened. Teachers need to rely on personal knowledge management to achieve effective integration of scattered knowledge resources, efficient use and sharing of resources with key values. Based on personal development willingness, teachers need to classify and process knowledge. In addition, it is necessary to organize such operations based on the internal relevance of knowledge to ensure the effectiveness of knowledge accumulation and sharing.

2) The process of tacit knowledge transformation should be given much more attention. Teachers must not only make clear explanations and explanations of explicit knowledge, but also explain a large amount of verbal expression knowledge as tacit knowledge. This type of tacit knowledge exists as the teacher's internal consciousness on the one hand, and on the other hand, it embodies the knowledge contained in teacher's subconsciousness. It effectively guides teacher's educational behavior and ensures that the tacit knowledge turns to the explicit knowledge. The continual transition leads to the formation of a kind of highly shared knowledge. These contents are the primary development goals in educational knowledge management.

3) The concept of knowledge transfer and exchange among teachers should be established. Knowledge management also exists as a process of knowledge acquisition and accumulation. In the process of knowledge communication, mutual sharing, and conversion, it needs to be processed with the help of human brain extraction and personal experience, and it can be transformed into a new form of knowledge with the help of collective wisdom so as to ensure the effective development of knowledge. In this process, there are detailed differences in different individuals' work history, knowledge accumulation, perspectives of research, and ways of thinking, which is also the fundamental bottleneck of the professional development and knowledge management for novice teachers. 


\section{A NEW MODEL: FOUR STRATEGIES FOR THE PROFESSIONAL DEVELOPMENT AND PERSONAL KNOWLEDGE MANAGEMENT OF NOVICE TEACHERS}

The effective accumulation of knowledge and experience of college teachers is inseparable from the Internet. What is more important for them is to find effective ways to add value to knowledge, establish a long-term knowledge management development plan, dynamically combine and apply knowledge from different disciplines, and form their own knowledge cycle development network, as shown in the Figure 3:

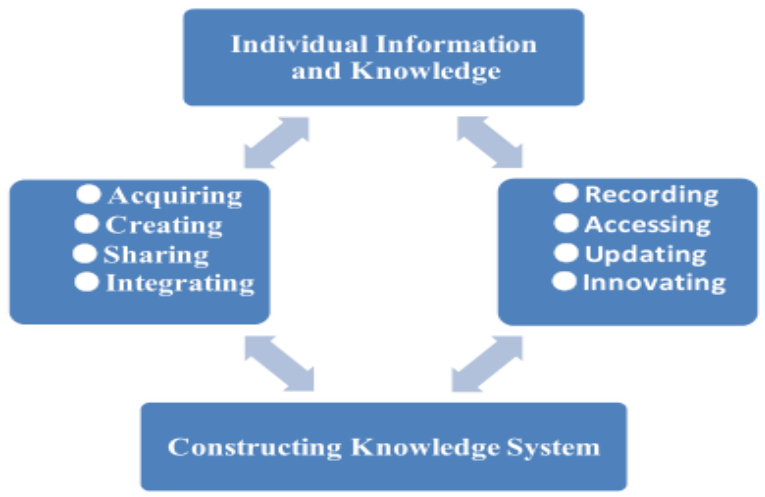

Figure 3 Knowledge Cycle Development Network

The new model of Personal knowledge management is suggested to implement the following strategies:

1) Think in a 'Internet' way, and actively learn platforms and tools for knowledge management. The Internet allows the rapid spread of knowledge, makes things more transparent, and standardized, while reducing duplication of labor and improving efficiency. The current individual's biggest capital is knowledge accumulation. Finding a method of knowledge management that can suit and improve teachers' ability to process information and knowledge can enhance their personal value. With the rapid update of technology, tools for personal knowledge management are also emerging very often. Cloud notes, cloud storage, efficiency management software, search engine and other tools and platforms can help individuals carry out effective knowledge management, make knowledge management a good personal habit, and promote learners' learning efficiency and quality.

2) Take full advantage of mobile, fragmented, and informal learning. With the further popularization of new media such as smart mobile networks, the diversification of information and the acceleration of the pace of life, reading methods and learning behaviors are changing, and mobile learning has become a new trend. With the emergence of massive amounts of information, mankind has entered into the era of fragmented learning. The idle time that the learner could not use in the past is fully utilized. Fragmented learning with the help of mobile terminals has gradually become a main learning method for people to acquire knowledge in infinite information fragments. Since knowledge search is arbitrary, the knowledge acquired is scattered, non-systemic, and fragmented. Therefore, learners are required to use information-based knowledge management tools to continuously record and store knowledge fragments.

3) Build a 'firewall' and form a whole-hearted learning habit in the Internet era. Learning is to optimize one's own internal and external networks. One's building a 'firewall' is very important. Fragmented learning requires learners to have a capacity of big data thinking and seek real meaningful and valuable information and knowledge from massive information. In the Internet era, the selection of knowledge fragments generally needs an open network platform to collect, edit, and classify knowledge fragments. Therefore, the authenticity and value of information and knowledge require learners to carefully choose and then classify and store them. The purpose is to accumulate and build their own 'knowledge base'.

4) Share knowledge so that it can be mastered and value-added. In the era of big data, fragmented learning is the 'dismantling' and 'reconstruction' of huge amounts of network information. A personal knowledge system can be constructed with the help of Mind Maps, microclasses, and MOOCs platforms to facilitate the collection and indexing of knowledge, and at the same time to use the Internet to conduct knowledge dissemination and knowledge realization. Establishing a learning model for knowledge sharing is worthwhile for novice teachers to explore the source of the problem more deeply, enhance the mastering of knowledge, and improve personal competitiveness. Personal knowledge management is an organic and continuous system, and new knowledge continues to 'flow' into it through the Internet. Thus, the updating knowledge base can provide support for knowledge reproduction, contribution and innovation, so that the personal knowledge structure can meet the needs of the times and benefit social development.

The core of teacher's personal knowledge management is the accumulation, communication and sharing of tacit knowledge. Teacher's tacit knowledge is self-constructed, dynamic and generative knowledge, and it is know-how knowledge. Teachers need to demonstrate tacit knowledge more extensively and deeply through teaching practice. Knowledge management fulfils the various functions that are played after effective management of knowledge, such as knowledge creation, acquisition, storage, sharing, integration, value proliferation, and transfer [6]. Personal knowledge management can be a new concept and method of knowledge management, which can turn all kinds of information readily available by individuals into more 
valuable knowledge, and finally teachers apply it in their own work and life.

\section{CONCLUSION}

To sum up, the key to the success of the personal professional development of college/university's novice teachers lies in how to effectively engage oneself in the growth of knowledge and with professional growth. Only with the help of information technology for open learning system and knowledge management strategy can they achieve better professional development, keep up with the pace of the times and meet the different needs of students. Building a systematic knowledge system has very bright prospects. The knowledge management of novice teachers under the background of 'Internet +' depends on their open learning, collaboration and innovation, which generally reflects the following development trends: socialization of learning; process coordination; personalization of management; dominance of knowledge [7].

\section{ACKNOWLEDGMENTS}

This research is funded by The Project of Teaching Reform Research in Jiangxi Colleges and Universities (Grant No.: JXJG-09-17-25) and The Project of Humanities and Social Sciences Planning in Jiangxi Colleges and Universities (Grant No.: SH1111).

\section{REFERENCES}

[1] Day, R. E. (2005). Clearing up "implicit knowledge": Implications for knowledge management, information science, psychology, and social epistemology. Journal of the American Society for Information Science and Technology, 56(6), 630-635.

[2] Chen Baoqi. Research on the Professional Development Strategy of University Teachers Based on the Perspective of Knowledge Management, Journal of Higher Education, 2017(8), 154-155/57.

[3] Edwards J.S. Knowledge Management: Theories and Practices. In: Fedeli M., Bierema L. (eds) Connecting Adult Learning and Knowledge Management. Knowledge Management and Organizational Learning, vol 8. Springer, Cham, 2019.

[4] Durst, S., \& Zieba, M. (2019). Mapping knowledge risks: Towards a better understanding of knowledge management. Knowledge Management Research \& Practice, 17(1), 1-13.

[5] Heisig, P. (2009). Harmonisation of knowledge management. Journal of Knowledge Management, 13(4), 4-31.

[6] Koenig, M. E. D. (2002). The third stage of KM emerges. KMWorld, 11, 20-21.

[7] Yan Wang. Research on the Professional Development Strategy of New Teachers Based on the Cloud Environment. Theory and Practice of Education, 2012(14), 19-22. 